\title{
ВНУТРЕННИЙ АУДИТ - ЭТИЧЕСКАЯ НОРМА ПОСТРОЕНИЯ ЭФФЕКТИВНОЙ СИСТЕМЫ КОРПОРАТИВНОГО УПРАВЛЕНИЯ
}

\author{
(c) 2020 Туруев Игорь Борисович \\ доктор экономических наук, профессор кафедры «Банки, денежное обращение и кредит» \\ МГИМО (Университет) МИД РФ, Россия, Москва \\ E-mail:i.turuev@inno.mgimo.ru
}

Целью работы является изучение подходов в построении эффективного внутреннего аудита, который стал неотъемлемым фактором успешной деятельности компаний и финансовых институтов. В статье даны рекомендации по формированию высокотехнологичной системы контроля собственником посредством аудита основных бизнес-процессов компании в условиях нарастания значимости рыночных рисков и ускорения процессов в глобальной экономике на платформе финансовотехнологических инноваций.

Ключевые слова: внутренний аудит, комплаенс, акционеры, COSO, риск-ориентированный подход, независимость.

\section{Методология}

В работе автор использует качественный анализ эволюции взглядов на построение эффективной системы корпоративного управления и необходимости интеграции контроля собственников. Исследуются публикации в этой области с акцентом на роль внутреннего аудита в анализе эффективности принятых решений и соблюдения требований регулятора. Автором использованы библиометрические исследований публикаций по темам внутреннего аудита, внутреннего контроля, рекомендации международных институтов.

В последние годы значительно возрос интерес собственников компаний (как частных, так и государственных) к развитию внутреннего контроля. Дело не только заключается в том, что усиливается пруденциальный надзор за деятельностью компании. Существует устойчивая тенденция в оценке наличия эффективной системы внутреннего контроля в корпорации как фактора, увеличивающего стоимость самой компании. Это позволяет собственникам быть уверенными в достоверности отчетности, контролировать деятельность компании на соответствие заявленным финансовым и стратегическим целям, снижать издержки по привлечению ресурсов, способствует повышению финансовой устойчивости и конкурентоспособности. Большинство специалистов сходятся во мнении, что внутренний контроль стал неотъемлемой частью современных подходов к управлению корпорациями. Комитетом спонсорских организаций Комиссии Тредуэя сформулированы основные принципы построения эффективного внутреннего контроля. В национальных законодательных актах отражено практическое преломление принципов, изложенных комитетом и иными авторитетными международными организациями в контексте конкретных правовых национальных ландшафтов (Федерального закона от 26.12.1995 № 208-Ф3 «Об акционерных обществах», 156-Ф3 «Об инвестиционных фондах», ФЗ от 8 августа 2001 г. и т.д). Практические аспекты реализации положений отражаются в ведомственных подзаконных актах (Методические рекомендации по формированию Положения о вознаграждениях и компенсациях членов Ревизионной комиссии акционерных обществ с участием Российской Федерации утверждены приказом Росимущества от 09.07.2014 № 253) и внутренних нормативных документах организаций.

\footnotetext{
Методология построения внутреннего контроля

Современный бизнес меняется:

- Для движения капитала стираются границы, крупный бизнес становится все более глобальным, одновременно усиливается государственный контроль за соблюдением законодательства и уплатой налогов;

- Все большее значение приобретают цифровые технологии, что влияет на организацию бизнеса. Появляются многочисленные технологические стартапы;

- Появляется необходимость усиливать информационную безопасность.

В тоже время в теории организации вну-
} 
треннего контроля значительных изменений не произошло. Одной из самых известных моделей внутреннего контроля является модель COSO. Эта модель основывается на системном подходе, в основе которого заложено 17 принципов, представленных в 2013 году Комитетом спонсорских организаций Комиссии Тредуэя (Committee of Sponsoring Organizations of the Treadway Commission, COSO), соблюдение которых позволяет создавать эффективный внутренний контроль. Принципы сгруппированы в 5 категорий.

Первая категория - контрольная среда включает в себя приверженность честности и этическим ценностям, независимость совета директоров от менеджмента и надзор за системой внутреннего контроля со стороны совета директоров, определение менеджментом под надзором совета директоров оптимальной организационной структуры, распределение полномочий и ответственности для достижения целей, заинтересованность организации привлекать, развивать и сохранять компетентный персонал, четкое разграничение полномочий и ответственности между сотрудниками.

Вторым компонентом является оценка рисков. Он включает в себя наличие ясных целей, позволяющих идентифицировать риски, их анализ для дальнейшего управления, при оценке рисков рассмотрение возможного мошенничества, оценка влияний изменений на систему внутреннего контроля.

К третьей категории относятся принципы контроля. Она включает в себя выбор и применение контрольных процедур, способствующих уменьшению рисков достижения целей, выбор и применение контрольных процедур в отношении информационных технологий, введение в действие контрольных процедур через внутренние документы.

Четвертая категория включает принципы, связанные с информацией и коммуникациями, получение и использование релевантной и качественной информации для поддержания функционирования внутреннего контроля, наличие коммуникаций внутри организации, в том числе в отношении поддержания функционирования внутреннего контроля, наличие коммуникаций с внешними сторонами относительно вопросов, влияющих на функционирование внутреннего контроля.

Последний, пятый блок - мониторинг - включает выбор, разработку, применение методов оценки, позволяющих убедиться в наличии всех компонентов внутреннего контроля и их надлежащем функционировании, а также сообщение о всех недостатках внутреннего контроля тем сторонам, которые могут принять надлежащие меры, включая топ-менеджмент и совет директоров.

Принципы корпоративного управления предполагают, что надзор за работой компании и ее менеджмента со стороны акционеров осуществляет совет директоров. Наличие квалифицированного совета директоров обеспечивает контроль за деятельностью компании по самым ключевым вопросам. Для многих компаний обязательным является наличие независимых директоров, т.е. директоров, независимых от должностных лиц общества, не входящих в число менеджеров организации и не имеющих личного интереса в обществе. Так, для включения акций эмитента в котировальный список первого (высшего) уровня Положением о допуске ценных бумаг к организованным торгам, утверждённым Банком России 24.02.2016 за № 534-П, определены следующие требования к организации работы совета директоров (наблюдательного совета):

- количество независимых директоров в совете директоров должно составлять не менее одной пятой состава совета директоров и не может быть меньше трех;

- советом директоров эмитента должен быть сформирован комитет по аудиту, возглавляемый независимым директором.

Требования к квалификации независимых директоров лежат в основном в области экономики и финансов, при этом пока нет установившихся практик в отношении цифровых компаний.

\section{Контрольные механизмы собственников за деятельностью компаний.}

В российской практике еще одним органом, призванным осуществлять контроль за финансово-хозяйственной деятельностью компании, является ревизионная комиссия. Возможность ее создания в соответствии с уставом предусматривается как законом об акционерных обществах (с п. 1 ст. 85 Федерального закона от 26.12.1995 № 208-ФЗ «Об акционерных обществах»), так и законом об обществах с ограниченной ответственностью (п. 6 ст. 32 Феде- 
рального закона от 08.02.1998 N 14-ФЗ «Об обществах с ограниченной ответственностью»). Многие компании используют механизм ревизионных комиссий для организации внутреннего контроля внутри группы. Законодательство предоставляет членам ревизионных комиссий право получать доступ к документам общества, что делает их удобной формой контроля со стороны головной компании. Сотрудники головной организации могут избираться членами ревизионных комиссий компаний, входящих в группу, и проводить проверки. Такой подход использует Росимущество при проверке компаний с госучастием и рекомендует госкомпаниям для проверок компаний, входящих в группу. Росимущество разработало следующие документы, регламентирующие деятельность ревизионных комиссий:

- Методические рекомендации по формированию Положения о Ревизионной комиссии акционерного общества с участием Российской Федерации (Приказ Росимущества от 16.09.2014 N 350);

- Методические рекомендации по формированию Положения о вознаграждениях и компенсациях членов Ревизионной комиссии акционерных обществ с участием Российской Федерации (Приказ Росимущества от 09.07.2014 N 253);

- Методические рекомендации по организации проверочной деятельности Ревизионных комиссий акционерных обществ с участием Российской Федерации (Приказ Росимущества N 254 от 26.08.2013).

Хотя эти документы разработаны для компаний с госучастием, они могут использоваться как методологическая поддержка всеми компаниями, желающими использовать механизм ревизионных комиссий. Вместе с тем, в соответствии с пп. 4 п. 3 ст. 66.3 Гражданского кодекса РФ, по решению участников (учредителей) непубличного общества (как ООО так и АО), принятому единогласно, в устав общества могут быть включены положения об отсутствии в обществе ревизионной комиссии или о ее создании исключительно в случаях, предусмотренных уставом общества.

В основе организации внутреннего контроля по-прежнему лежит концепция «трех линий защиты». Данная концепция предполагает, что на первой линии располагаются элементы контроля, которые «зашиты» в сами бизнес-процессы, выполняются бизнес-подразделениями через выполнение регламентов, грамотные разделения полномочий и обязанностей.

На второй линии защиты находятся контрольные подразделения, которые выполняют контрольные функции, но при этом встроены в бизнес-процесс: финансовый департамент в части финансового контроля, департамент рисков, департамент безопасности, подразделение внутреннего контроля (комплаенс-подразделение). Данные подразделения подчинены менеджменту, в ряде случаев должны контролировать все операции в сплошном порядке.

Третью линию защиты представляет подразделение внутреннего аудита, которое является независимым от менеджмента, подчиняется непосредственно совету директоров, осуществляет проверки, самостоятельно определяя их направления. Такие проверки обычно носят последующий характер и имеют целью оценку эффективности внутреннего контроля и качества корпоративного управления. Подразделения внутреннего аудита не могут осуществлять иные операции, так как от этого пострадает их независимость. Деятельность внутреннего аудита может проверяться независимыми квалифицированными экспертами, результаты такой проверки докладываются совету директоров.

\section{Менеджмент и внутренний контроль.}

Как показали опросы, проводимые консультационными фирмами, даже в крупных компаниях на практике многие руководители до сих пор считают, что система внутреннего контроля сводится к подразделениям внутреннего контроля - службе внутреннего контроля и службе внутреннего аудита. В действительности последние представляют собой только часть системы внутреннего контроля, хотя и очень важную. Результаты еще одного интересного опроса, проводимого консалтинговыми компаниями, показывают, что первые лица, руководство компании часто не знают какие операции проводятся их компаниями и не могут до конца оценить их риски. Так, на вопрос есть ли у них производные финансовые инструменты (опрос проводился после кризиса 2008 года) исполнительное руководство отвечало, что нет, тогда как руководитель внутреннего аудита этой компании отвечал, что есть. К сожалению, даже там, где наличие внутреннего аудита обязательно, руководство компании не всегда умеет извлекать 
максимальную пользу из его деятельности, так как считает, что знает все, что ему нужно, про свой бизнес и не нуждается в альтернативной точке зрения и дополнительной помощи.

Развитие законодательной базы как за рубежом, так и в России направлено на формирование у собственников и компаний потребностей и умения использовать возможности внутреннего контроля. Закон Сарбейнса-Оксли требует от публичных компаний отчитываться о внутреннем контроле, этот отчет заверяется внешним аудитором.

В России значительную законодательную базу для организации внутреннего контроля разработало Росимущество. Напрямую документы Росимущества адресованы компаниям с госучастием, многие положения, соответствующие международной практике, обязательны для исполнения госкомпаниями и приняты директивами Правительства. Методические указания содержат требования к организации работы подразделений внутреннего аудита, комитетов по аудиту, внутреннего аудита группы компаний, антикоррупционного комплаенса. С другой стороны, этими материалами, разработанными на основе международной практики могут пользоваться все компании, желающие организовать адекватный внутренний контроль.

Совет директоров Банка России одобрил Кодекс корпоративного управления, который рекомендован к применению акционерными обществами, ценные бумаги которых допущены к организованным торгам.

\section{Линии защиты и их правовая локализация}

Рассмотрим организацию «трех линий защиты» в компании более детально.

Первая линия в наибольшей степени отражает особенности бизнеса в компании и от ее организации зависит эффективность бизнеса. Трудоемкие, неэффективные, «бумажные» процессы могут привести к катастрофическим ошибкам. Примером может служить вопиющий случай в космической отрасли, где причиной падения ракеты-носителя Протон стало применение заводом-изготовителем несоответствующего технологии припоя. Расследование показало, что это произошло в результате болезни кладовщика и отсутствия адекватного контроля за складским учетом. Контроли не сработали на всех этапах изготовления двигателя! С развитием компьютерных технологий и роботизации процессы первой линии защиты могут быть изменены, но принципы организации остаются следует избегать конфликта интересов, процессы должны быть адекватно регламентированы. Полномочия и ответственность должны быть должным образом разделены. Соответствующие изменения в процедуры и регламенты должны вноситься своевременно. Применение технологий дает бизнес-подразделениям соответствующие инструменты контроля. Даже полностью роботизированные производства взаимодействуют друг с другом и зависят от поставок, финансов, сбыта и т.д.

Говоря о второй линии защиты, мы остановимся на двух аспектах его организации. Есть подразделение, к деятельности которого в российской практике и сводился контроль внутри компании. Это контроль со стороны финансовой и бухгалтерской службы и главного бухгалтера. Особенность этого контроля - непрерывность, универсальность, системность. Такой контроль позволяет следить за эффективностью деятельности, сохранностью активов, целевым расходованием средств, а также инвестиционной деятельностью. Интересно проследить эволюцию контрольного аспекта бухгалтерской деятельности.

В соответствии со ст. 7 старой редакции Закона о бухгалтерском учете (129-ФЗ от 21.11.96) «главный бухгалтер обеспечивает соответствие осуществляемых хозяйственных операций законодательству Российской Федерации, контроль за движением имущества и выполнением обязательств. Без подписи главного бухгалтера денежные и расчетные документы, финансовые и кредитные обязательства считаются недействительными и не должны приниматься к исполнению. В случае разногласий между руководителем организации и главным бухгалтером по осуществлению отдельных хозяйственных операций документы по ним могут быть приняты к исполнению с письменного распоряжения руководителя организации, который несет всю полноту ответственности за последствия осуществления таких операций».

Действующая в настоящее время редакция закона о бухгалтерском учете (в редакции Федерального закона от 21.12.13 № 357-Ф3) не возлагает на главного бухгалтера таких задач и ответственности. В соответствии со статьей 9 «лицо, на которое возложено ведение бухгалтерского учета, и лицо, с которым заключен договор об 
оказании услуг по ведению бухгалтерского учета, не несут ответственность за соответствие составленных другими лицами первичных учетных документов совершимся фактам хозяйственной жизни».

Однако, в настоящее время за фальсификацию финансовых документов учета и отчетности финансовых организаций установлена ответственность в статье 172 Уголовного кодекса Российской Федерации (далее - УК РФ), в которой максимальное наказание за указанное правонарушение предусматривает лишение свободы на срок до четырех лет с лишением права занимать определенные должности или заниматься определенной деятельностью на срок до трех лет. В то же время, в действующей редакции указанной статьи не предусмотрена ответственность за фальсификацию финансовых документов учета и отчетности финансовых организаций, совершенную группой лиц по предварительному сговору или организованной группой, что не соответствует правоприменительной практике.

Правительством внесен в ГС ФС РФ 16.10.2017 Проект федерального закона № 286345-7 «О внесении изменений в статью 172.1 Уголовного кодекса Российской Федерации и статьи 160.1 и 165 Уголовно-процессуального кодекса Российской Федерации». Законопроект разработан во исполнение подпункта «а» пункта 14 Национального плана противодействия коррупции на 2016-2017 годы, утвержденного Указом Президента Российской Федерации от 1 апреля 2016 г. № 147, а также поручения Первого заместителя Председателя Правительства Российской Федерации И.И.Шувалова от 18 января 2017 г. № ИШ-П2-211 и направлен на дальнейшую реализацию рекомендаций по результатам оценки Российской Федерации в рамках 2-й фазы мониторинга выполнения Конвенции ОЭСР по борьбе с подкупом иностранных должностных лиц при осуществлении международных коммерческих сделок (Париж, 17 декабря 1997 года).

В этой связи, Законопроектом предлагается дополнить статью 172 УК РФ частью второй, устанавливающей наказание в виде штрафа в размере от трех миллионов до пяти миллионов рублей или в размере заработной платы или иного дохода осужденного за период от трех до пяти лет, либо лишения свободы на срок до семи лет с лишением права занимать определенные должности или заниматься определенной деятельностью на срок до трех лет за фальсифи- кацию финансовых документов учета и отчетности финансовых организаций, совершенную группой лиц по предварительному сговору или организованной группой.

Хотелось бы также обратить внимание на еще один элемент «второй линии защиты», который является относительно новым для российской практики. Это деятельность комплаенсподразделения. Наверно, можно утверждать, что первыми с необходимостью организовать комплаенс столкнулись российские банки, а также компании, привлекавшие средства на международных рынках капитала.

В настоящее время комплаенс в виде службы внутреннего контроля обязателен во всех банках, для компаний с госучастием Росимущество разработало Методические Указания в части организации внутреннего контроля для борьбы с коррупцией, который также включается в деятельность комплаенс-подразделения.

\section{Этические аспекты деятельности компла-} енс службы.

Остановимся на нескольких задачах комплаенс службы. Само слово комплаенс означает «соответствие». Комплаенс служба организовывает соблюдение компанией соответствия внешним законодательным требованиям и внутренним регламентам и политикам. Нарушение этих требований может привести как к значительным штрафам, так и репутационным потерям. В последние годы особое значение приобретает санкционный комплаенс. Если раньше такой контроль существовал только в банках, которые были обязаны следить за операциями своих клиентов, чтобы предотвращать отмывание денег и совершение незаконных операций компаниями и странами, находящимися под санкциями, то теперь такой контроль становится частью бизнеса производственных и сервисных компаний.

Санкции против частных лиц и организаций вводятся компетентными органами иностранных государств в соответствии с национальным законодательством. Это могут быть ограничительные меры, связанные с доступом на рынок капитала, блокированием денежных средств, арестом имущества, а также иные запреты и ограничения, которые принимаются в одностороннем порядке со стороны иностранного государства и не зависят от воли лиц, включенных в санкционный список.

Особое значение имеют санкции, налагае- 
мые США (список ведется Управлением по контролю за зарубежными активами (OFAC) Казначейства США), так как они являются фактически экстерриториальными. Американское казначейство рассматривает расчеты в долларах в нарушение санкций как использование финансовой системы США и налагает огромные штрафы. Так, например, в октябре 2015 было объявлено, что французский банк Credit Agricole выплатит американским властям 800 млн. долларов в рамках урегулирования расследования о нарушении этим финансовым институтом санкционных ограничений, введенных США в отношении Ирана и Судана. Американские власти обвиняют французский банк в незаконном осуществлении денежных переводов на иранские и суданские счета через филиалы Credit Agricole на территории США. По данным Bloomberg в результате заключения соглашения с американской юстицией банк полностью признает свою вину в нарушении закона США, касающихся санкций, что поможет ему избежать уголовного преследования. Также в 2015 году немецкий Commerzbank был оштрафован в США на 1,15 млрд. за несоблюдение санкционного режима против Ирана. Ранее, в 2014 году другой французский банк, BNP Paribas, уплатил штраф в сумме \$9 млрд. и признал себя виновным в нарушении американских санкций против Ирана, Судана и Кубы.

В настоящее время в отношении России действует ряд санкционных мер в связи с украинским кризисом. В частности, секторальные санкции США включают запрет на операции с капиталом и займами со сроком обращения/ погашения более 30 дней, запрет на операции с вовлечением лица, организации, банка из санкционного списка, юрисдикционная связь с США (т.е. использование долларов, вовлечение американских участников), запрет на экспорт товаров в Россию для нефтеразработки и нефтяной промышленности. Европейским компаниям запрещено работать на территории Крыма, которую ЕС и США рассматривают как территорию Украины. 21 июля 2017 года немецкий концерн Сименс объявил, что получил достоверную информацию о модернизации и перемещении в Крым четырех турбин, которые были поставлены летом 2016 года для проекта в Тамани (Краснодарский край). В компании утверждают, что это было сделано в нарушение контрактных обязательств. Концерн намерен добиться возвращения оборудования в Тамань и предотвратить новые поставки в Крым. В связи с указанным фактом ЕС добавил трех граждан России и три компании, вовлеченные в доставку газовых турбин в Крым, в список лиц, подпадающими под ограничительные меры в связи с действиями, подрывающими территориальную целостность, суверенитет и независимость Украины.

Все вышесказанное объясняет, почему функция организации санкционного комплаенса приобретает такое значение для банков и компаний. В рамках санкционного комплаенса целесообразно проверять: Статус контрагента, банков, участвующих в расчетах. При этом следует учитывать, что санкции могут распространяться в силу прямого указания закона или практики применения на лиц, имена которых не включены в соответствующие санкционные списки. Следует избегать операций, которые подпадают под существующие санкции или в отношении которых существует вероятность введения санкции.

Еще одной стороной деятельности комплаенс-подразделения становится комплаенс в области этических ценностей общества. Мы уже упоминали Кодекс корпоративного управления, рекомендованным к применению акционерными обществами, ценные бумаги которых допущены к организованным торгам. Кодекс указывает, что многие вопросы, связанные с корпоративным управлением, лежат за пределами законодательной сферы и имеют этический, а не юридический характер. Нормы гражданского законодательства устанавливают возможность при отсутствии применимого законодательства исходить из требований добросовестности, разумности и справедливости, требуют осуществлять гражданские права разумно и добросовестно, а также запрещают осуществлять гражданские права исключительно с намерением причинить вред другому лицу, а также действия в обход закона с противоправной целью.

Требований законодательства недостаточно, поэтому компании должны разрабатывать свои этические нормы. Здесь деятельность подразделения второй линии защиты пересекается с деятельностью Комитета по аудиту компании. В соответствии с п. 172 Кодекса одной из основных задач Комитета по аудиту Совета директоров является «контроль процедур, обеспечивающих соблюдение обществом требований законодательства, а также этических норм, правил и про- 
цедур общества, требований бирж».

Кодексом также рекомендовано Совету директоров создавать другие постоянно действующие или временные комитеты, в частности Комитет по этике. Методические рекомендации Росимущества по организации работы Комитетов по аудиту Совета директоров в акционерном обществе с участием РФ (утверждены приказом Росимущества от 20.03.2014 № 86) также относит к компетенции Комитета по аудиту Совета директоров рассмотрение вопросов, относящихся к процедурам обеспечения компанией соблюдения требований законодательства, а также этических норм, правил и процедур компании, требований Банка России, фондовых бирж (если применимо) (комплаенс). Таким образом соблюдение этических норм становится одним из важных вопросов корпоративного управления, а рассмотрение вопросов, связанных с их выработкой и контролем отнесено к компетенции самого высокого уровня в иерархии корпоративного управления - Совета директоров. Основную практическую работу выполняет комплаенс-подразделение: участвует в разработке внутренних политик и правил, например, кодекса корпоративной этики, проводит обучающие мероприятия, рассматривает вопросы конфликта интересов, готовит материалы на рассмотрение на комитете по этике и на заседании Совета директоров.

Отдельным направлением в этическом комплаенсе является предупреждение и профилактика коррупции. В целях повышения качества корпоративного управления в акционерных обществах с государственным участием в части организации системы управления рисками и внутреннего контроля в области предупреждения и противодействия коррупции в акционерных обществах Приказом Росимущества от 02.03.16 № 80 были также утверждены Методические рекомендации по организации управления рисками и внутреннего контроля в области предупреждения и противодействия коррупции.

В соответствии с п. 2.10 указанных Методических рекомендаций «подразделение комплаенс/комплаенс-менеджер решает поставленные перед ним в обществе задачи по координации и обеспечению разработки и поддержания мероприятий по предупреждению и противодействию коррупции путём развития корпоратив- ных этических ценностей общества».

Кроме этого, комплаенс подразделения, подразделения внутреннего контроля рассматривают процессы с точки зрения наличия в них коррупционного риска, например, вопросы, связанные с закупками, предоставлением скидок, и выносят предложения о совершенствовании процессов на рассмотрение менеджмента.

K третьей линии защиты относится деятельность подразделения внутреннего аудита. Под внутренним аудитом в соответствии с определением, предлагаемым Институтом внутренних аудиторов (Институт внутренних аудиторов международная профессиональная ассоциация, призванная развивать профессию внутреннего аудитора и поддерживать внутренних аудиторов во всем мире. Институт объединяет около 170000 человек в 100 странах, которые работают в области внутреннего аудита, риск менеджмента, управления, внутреннего контроля и других сферах) понимается деятельность по предоставлению гарантий и консультаций, направленная на совершенствование деятельности организации. Данное подразделение должно работать с соблюдением принципов независимости и объективности. Независимость достигается путем прямого доступа к руководству компании и Совету директоров, функциональной подотчетностью Совету директоров. Подразделение внутреннего аудита не должно участвовать ни в какой производственной деятельности компании, не быть связанным ни с одним из проверяемых подразделений компании. Внутренний аудит в процессе проверок анализирует и оценивает как систему управления рисками состояние системы внутреннего контроля и качество корпоративного управление.

\section{Выводы}

Построение высокоэффективной системы корпоративного управления возможно только при условии соблюдения основных принципов построения внутреннего контроля бизнеспроцессов предприятия. Внутренний аудит приобрел статус обязательной нормы корпоративной культуры и является, пожалуй, объективным инструментом контроля собственника при обеспечении независимости, достаточности ресурсов и технологичности его деятельности. 


\section{Библиографический список}

1. Положение Банка России от 16 декабря 2003 г. N 242-П «Об организации внутреннего контроля в кредитных организациях и банковских группах» с последующими изменениями и дополнениями.

2. http://www.coso.oxgjdocuments/cosoermexecuti vesunimary.pdf

3. Кодекс корпоративного управления, 2014, п. 85.

4. OECD Corporate governance principles, 2004. www.oecd.org

5. Управление компанией в условиях кризиса. Пособие для членов советов директоров, Международная финансовая корпорация, 2010.

6. С использованием Guide to Enterprise Risk Management. http://www.ucop.edu/enterprise-risk-management/ files/protiviti faqguide.pdf

7. Приказ Росимущества от 20.03.2014 № 86 «Об утверждении Методических рекомендаций по организации работы Комитетов по аудиту Совета директоров в акционерном обществе с участием Российской Федерации»

8. Методические рекомендации по формированию Положения о вознаграждениях и компенсациях членов Ревизионной комиссии акционерных обществ с участием Российской Федерации утверждены приказом Росимущества от 09.07.2014 № 253.

9. Статья 82 Федерального закона от 26 декабря 1995 г. № 208-ФЗ «Об акционерных обществах» (закон об АО) и статья 45 Федерального закона от 8 февраля 1998 г. № 14-Ф3 «Об обществах с ограниченной ответственностью» (закон об ООО).

10. 156-Ф3 «Об инвестиционных фондах», ФЗ от 8 августа 2001 г. N 134- Ф3 «О защите прав юридических лиц и индивидуальных предпринимателей при проведении государственного контроля (надзора)», ГПК РФ

11. «Управление рисками, аудит и внутренний контроль. Практические рекомендации», Под редакцией А. Филатова, Э. Джураева Москва 2015 год.

12. ФЗ N 395-1 «Закон о банках и банковской деятельности» от 2 декабря 1990 г.

13. «Как изменятся финансы в ближайшее время» С. Шароян, РБК, Финансы 21.01.2016

14. https://www.imolvencydirect.bis.gov.uytechmcalman 